\title{
A Study on Student Perception of Virtual Dissection Table (Anatomage) at GSL Medical College, Rajahmundry
}

\author{
Amit Singh Bharati ${ }^{1}$, Surya Kumari ${ }^{2}$, V. Subhashini Rani ${ }^{3}$ \\ ${ }^{1}$ Assistant Professor, ${ }^{2}$ Associate Professor, ${ }^{3}$ Professor and Head, GSL Medical College, Rajahmundry.
}

\section{Abstract}

Introduction: The Anatomage Table is the only fully segmented real human 3D anatomy system. Individual structures are reconstructed in accurate 3D and it helps the medical pre-clinical students to explore and understand human anatomy like never before and even beyond a cadaveric dissection. Anatomage is an interface that affords students the opportunity to explore life-size anatomy on an interactive 3D table. ${ }^{[1]}$ Aim and Objective: The aim of the study was to gather student opinion regarding this virtual dissection table (Anatomage) technology. Subjects and Methods: A questionnaire addressing the role of the Anatomage table in anatomy education and its comparison with various other learning modality was completed by 150 pre-clinical medical students. A free hand comment section was also included in the study. Results: $96 \%$ of students strongly preferred the cross sectional planes and images of Anatomage over still images of text book in learning Anatomy. 95\% of students strongly agreed that the ability of Anatomage to rotate and dissect is better in visualizing the body systems. $90 \%$ of students strongly agreed that Anatomage can be an adjunct or added tool to cadaveric dissection but not its replacement. $48 \%$ of students believe Anatomage visualisation is better than real dissected structures. Conclusion: Anatomage can play an important role in the acquisition of 3D knowledge of Anatomy and promises to be a useful added tool to traditional learning modalities, which still ranked high. This feedback also reveals that students are fascinated with the inclusion of Anatomage in their curriculum as it helps them in understanding, revising and learning in a better way than before. This virtual dissection table can be of immense help in medical colleges where sufficient number of cadavers are not available for Anatomical study.

Keywords: Medical student, Virtual Dissection Table.

Corresponding Author: Dr. Surya Kumari N, Associate Professor, GSL Medical College, Rajahmundry.

Received: November 2018

Accepted: November 2018

\section{Introduction}

A solid understanding of normal anatomy and function enhances students abilities to recognize how normal function may be affected when the anatomy has been altered as the result of a developmental defect, disease, or trauma. ${ }^{[1]}$

For imaging science students, learning anatomy provides a basis for critical thinking, reasoning and problem solving skills that are essential in the clinical environment. ${ }^{[2]}$

The best "model" for investigating human anatomy has always been the human cadaver itself, because, in most cases, all the parts are there in the correct arrangement, the fine membranous and facial elements are intact, and the presentation of structures (soft, hard, smooth, rough, dry, moist) is accurate.

However, in today's regulated and socially conscious institutions, access to a cadaver may be limited through budgetary or social issues, or, even if a cadaver is available, presentation of the desired cadaveric anatomy may be confusing, such as that of the pelvic spaces and fascia. ${ }^{[3]}$ These issues can be addressed through the use of Virtual dissection table or 3D Anatomical models.

The Anatomage Table [Photograph 1] is a life-size virtual dissection table that displays gross anatomy models reconstructed from cadavers. ${ }^{[4]}$ The Anatomage Table is the only fully segmented real human 3D anatomy system.

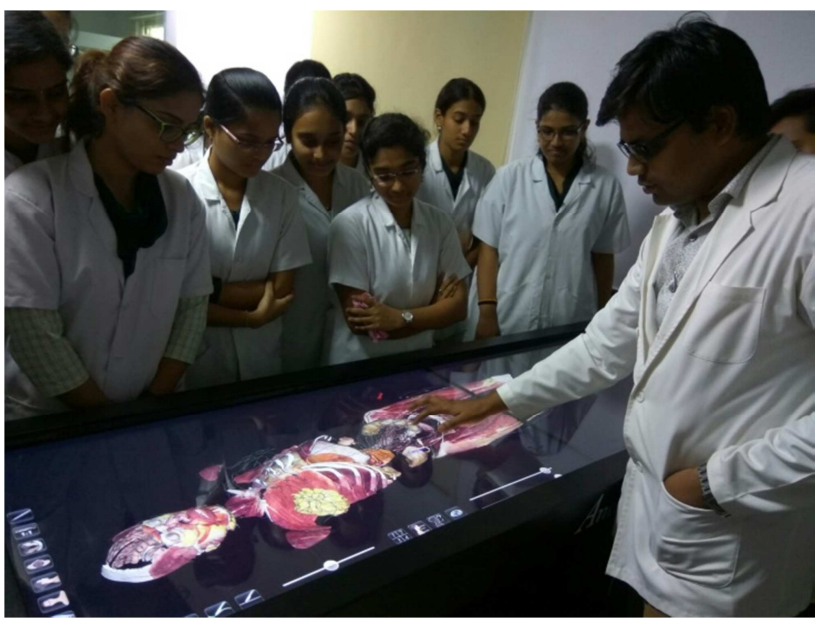

Photograph 1: Anatomage Table.

Individual structures are reconstructed in accurate $3 \mathrm{D}$ and it helps the medical pre-clinical students to explore and 


\section{Bharati et al; Student Perceptian of Virtual Dissection I alle}

understand human anatomy like never before and even beyond a cadaveric dissection.

Research work on Anatomage and medical imaging is very limited as only few medical institutions have adopted this technology.

The virtual dissection table Anatomage was introduced for the first time at GSL Medical college, Rajahmundry for the academic year 2016-17. Questionnaire was framed to know the perception of students regarding this newly introduced Anatomage technology.

\section{$\underline{\text { Aim }}$}

The aim of the study was to gather student opinion regarding this virtual dissection table (Anatomage) technology.

\section{Subjects and Methods}

A questionnaire addressing the role of the Anatomage table in anatomy education and its comparison with various other learning modalities was completed by 150 pre-clinical medical students. A free hand comment section was also included in the study

\begin{tabular}{|c|c|c|}
\hline Questionairre & Observation & \\
\hline $\begin{array}{l}\text { 1.Do you think that the cross } \\
\text { sectional planes and images of } \\
\text { ANATOMAGE (3D) is better } \\
\text { in understanding Anatomy } \\
\text { than the still images of text } \\
\text { book (2D)? }\end{array}$ & $\begin{array}{l}\text { Yes } \\
(96 \%)\end{array}$ & $\begin{array}{l}\text { No } \\
(4 \%)\end{array}$ \\
\hline
\end{tabular}

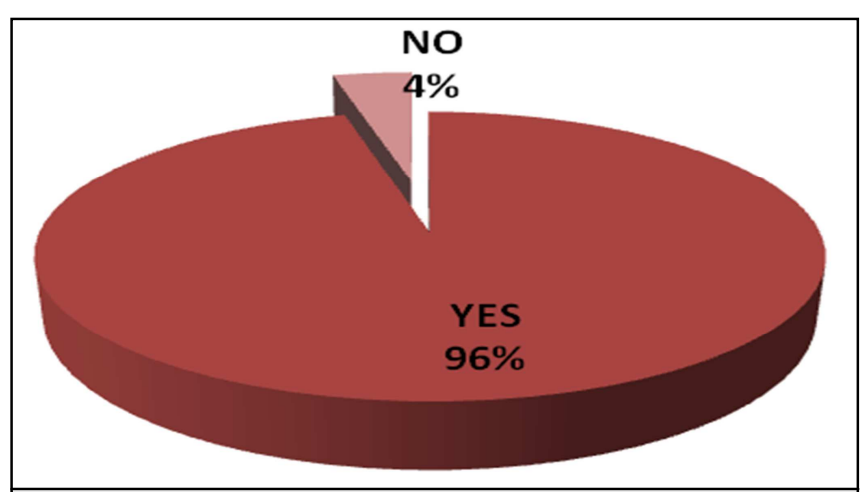

\begin{tabular}{|c|c|c|}
\hline Questionairre & Observation & \\
\hline $\begin{array}{l}\text { 2.Do you think that the ability } \\
\text { to rotate and dissect in } \\
\text { ANATOMAGE is better in } \\
\text { visualizing the body systems? }\end{array}$ & $\begin{array}{l}\text { Yes } \\
(95 \%)\end{array}$ & $\begin{array}{l}\text { No } \\
(5 \%)\end{array}$ \\
\hline
\end{tabular}

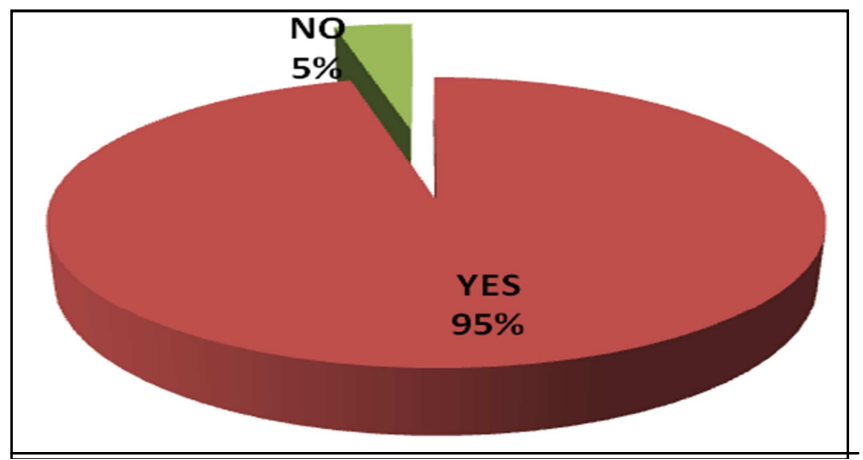

\begin{tabular}{|c|c|c|}
\hline Questionairre & Observation & \\
\hline $\begin{array}{l}\text { 3. What do you think is easy } \\
\text { to understand Cadaveric } \\
\text { dissected structures or } \\
\text { Anatomage visuals? }\end{array}$ & $\begin{array}{ll}\text { Cadaveric } & \text { dissected } \\
\text { structures } & \\
(52 \%) & \end{array}$ & $\begin{array}{l}\text { Anatomage } \\
\text { dissected } \\
\text { visuals } \\
(48 \%)\end{array}$ \\
\hline
\end{tabular}

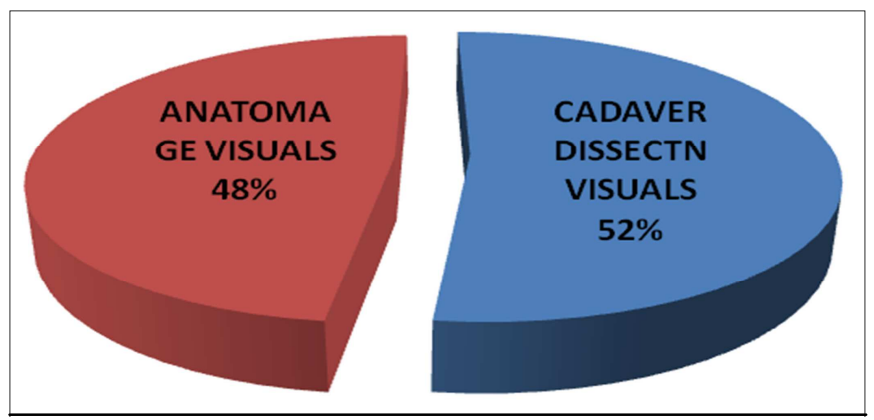

\begin{tabular}{|c|c|c|c|}
\hline Questionairre & Observation & & \\
\hline $\begin{array}{l}\text { 4. What do you think is } \\
\text { the best advantage of } \\
\text { Anatomage? } \\
\text { a. Ability to reconstruct } \\
\text { image. } \\
\text { b. No exposure to } \\
\text { infection } \\
\text { c. No irritation of eyes } \\
\text { as formalin is not } \\
\text { involved }\end{array}$ & $\begin{array}{lr}\text { Ability } & \text { to } \\
\text { reconstruct } & \text { image. } \\
(80 \%) & \end{array}$ & $\begin{array}{l}\text { b. No } \\
\text { exposure } \\
\text { to } \\
\text { infection. } \\
(14 \%)\end{array}$ & $\begin{array}{l}\text { No } \\
\text { irritation } \\
\text { of eyes } \\
\text { as } \\
\text { formalin } \\
\text { is not } \\
\text { involved. } \\
(6 \%)\end{array}$ \\
\hline
\end{tabular}
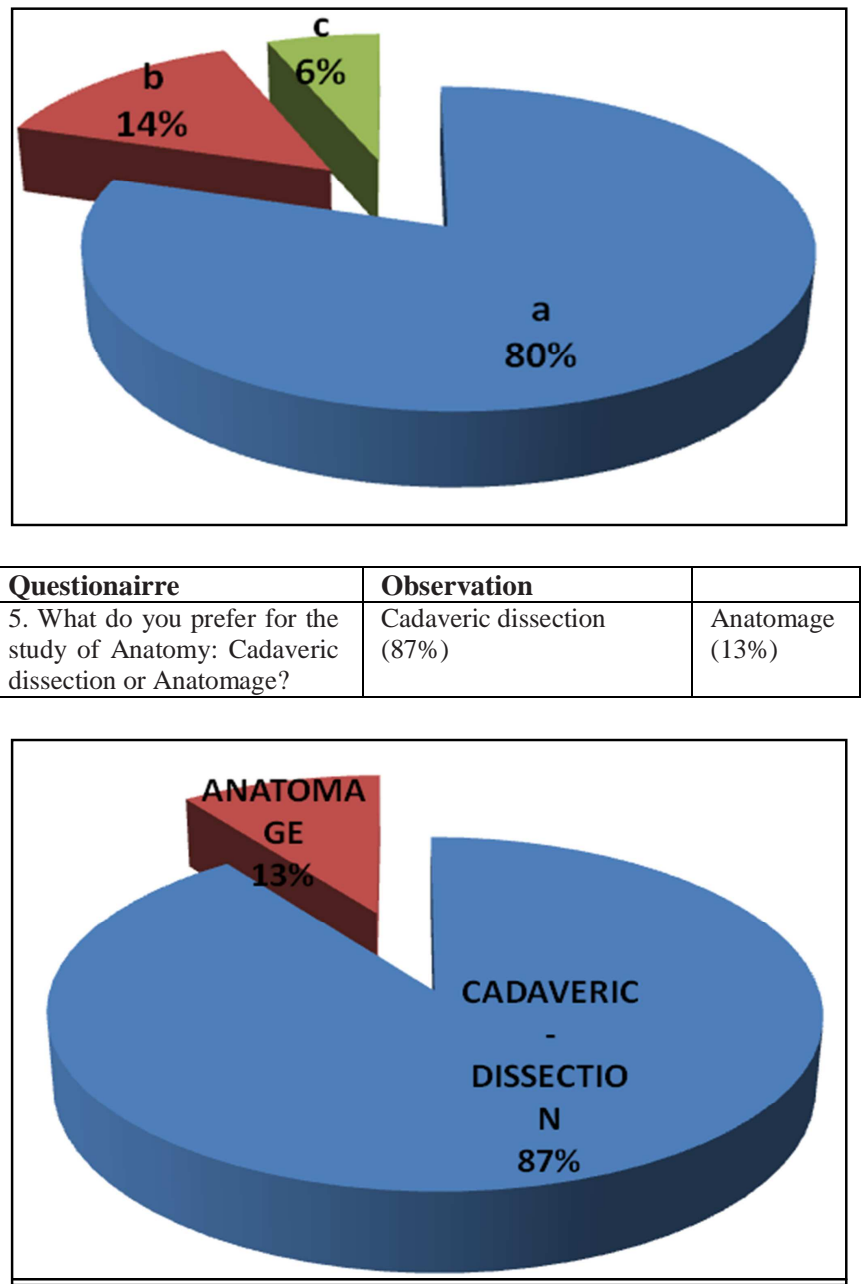


\begin{tabular}{|l|l|l|}
\hline Questionairre & Observation & \\
\hline 6. What do you think : & $\begin{array}{l}\text { An added tool } \\
(90 \%)\end{array}$ & $\begin{array}{l}\text { Replacement } \\
\text { for } \\
\text { dissection } \\
\text { tool or a replacement for }\end{array}$ \\
$\begin{array}{l}10 \%) \\
\text { dissection? }\end{array}$ & \\
\hline
\end{tabular}

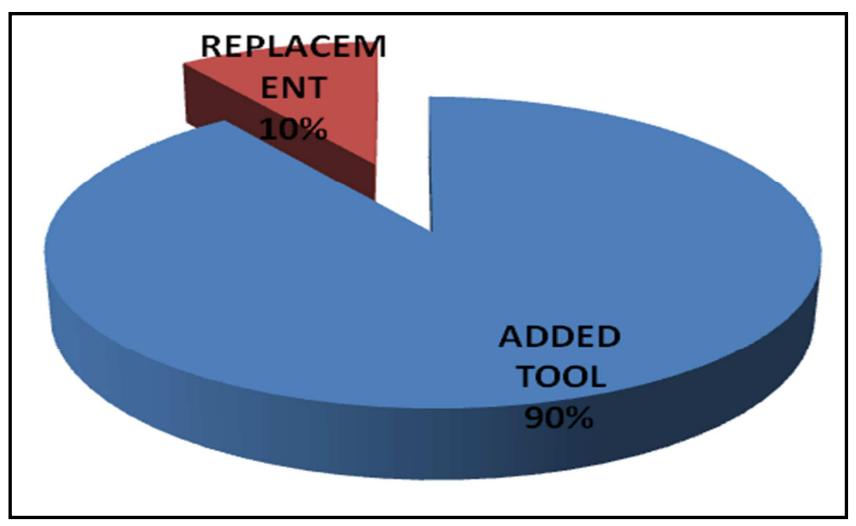

\section{Advantages}

1. Ability to study Anatomy in a 3D view.

2. Ability to study CT/MRI images which is helpful for clinical practice.

3. Ability to study those regions which are difficult to dissect, e.g Pelvic spaces.

4. Ability to study histology scans.

5. Ability to save clippings and replay when needed.

\section{Disadvantages}

1. The consistency of an artery, a vein or a nerve cannot be made out as one cannot palpate these in Anatomage.

2. Colour of the tissues in Anatomage model may not match with the actual cadaver.

3. Students will be required to spend more time to get acquainted with Anatomage technology.

\section{Results}

- $96 \%$ of students strongly preferred the cross sectional planes and images of Anatomage over still images of text book in learning Anatomy.

- $95 \%$ of students strongly agreed that the ability of Anatomage to rotate and dissect is better in visualizing the body systems.

- $90 \%$ of students strongly agreed that Anatomage can be an adjunct or added tool to cadaveric dissection but not its replacement.

- $48 \%$ of students believe Anatomage visualisation is better than real dissected structures.

Many students had an opinion that Dissection combined with Anatomage helped them understand Anatomy even better.

\section{Discussion}

There has been an increase use of modern technology in learning Anatomy ever since the introduction of 3D imaging and virtual dissection table. But there is very limited research done on this newer technology and data in the literature is also very less. The present study is done to know the perception of students on this newly introduced Virtual Dissection Table (Anatomage). Tanya Custer conducted a study on Utilization of Anatomage Virtual dissection Table in education of imaging science students. ${ }^{[4]}$ she selected 17 imaging students for the study and students were questioned at different intervals of their semester session to get their feedback. To the question on whether Anatomage table benefitted to their learning, $14(82.35 \%)$ agreed in the midsemester, $15(88.24 \%)$ agreed at the end of semester and $16(94.1 \%)$ agreed and 1 undecided at the final months of spring semester. To the question on whether Anatomage table had positive influence on their classroom experience, $11(65 \%)$ in mid-semester agreed, 15(88\%) at the end of semester agreed and $15(88 \%)$ at the final months of spring semester agreed. To the question on whether Anatomage table had better prepared them to enter health profession, $16(94 \%)$ agreed in mid-semester, 14(82\%) agreed at the end of semester and $16(94 \%)$ agreed at the final months of spring semester.

Ian Chan conducted a comparitive study on Effectiveness of learning Anatomy and Medical imaging using the Anatomage table and compared it to Prosection. ${ }^{[5]} \mathrm{He}$ conducted a randomized control trial comparing Anatomage and prosection. He selected 16 undergraduate students for his study, he found that Anatomage based instruction scored high in identifying the relative location of anatomy and in identifying imaging planes. Qualitative feedback suggested that Prosection group found that it was helpful in physically handle knee joint and to understand ligaments in prosected specimen while Anatomage group found that more time to process the learning content would benefit them.

The present study correlates with Fyfe G et al in which it was found that more students using Anatomage were of the opinion that Anatomage was moderately or very helpful to them in understanding the relative sizes of different organs and the relationships between organs. ${ }^{[6]}$

The present study correlates with and supports the findings of J. Brown et al, ${ }^{[7]}$ where $85 \%$ of students agreed that anatomy was an interesting subject and $98 \%$ agreed that it was an important component of medical education. $63 \%$ believed that Anatomage helped to improve their knowledge and understanding of 3D anatomy. 78\% agreed that the interactive nature of Anatomage made learning anatomy more engaging

In the present study, $96 \%$ of students strongly preferred the cross sectional planes and images of Anatomage over still images of text book in learning Anatomy. 95\% of students strongly agreed that the ability of Anatomage to rotate and dissect is better in visualizing the body systems.

\section{Conclusion}

- Anatomage can play an important role in the acquisition of 3D knowledge of Anatomy and promises to be a useful added tool to traditional learning modalities, which is still ranked high.

- This feedback also reveals that students are fascinated with the inclusion of Anatomage in their curriculum as it helps them in understanding, revising and learning in a better way than before. 


\section{Bharati et al; Student Perceptian of Virtual Dissection Talle}

Though our study is by no means exhaustive, it does provide a glimpse into the new technology of 3D virtual imaging (Anatomage) and this virtual dissection table can be of immense help in medical colleges where sufficient number of cadavers are not available for Anatomical study.

\section{References}

1. Miller SA, Perrotti W, Silverthorn DU, Dalley AF, Rarey KE, et al. (2002) From college to clinic: reasoning over memorization is key for understanding anatomy. The Anatomical Record 269: 69-80.

2. Fredieu JR, Kerbo J, Herron M, Klatte R, Cooke M, et al. (2015) Anatomical Models: a Digital Revolution. Medical Science Educator 25: 183-194.

3. Creswell JW (2013) Qualitative Inquiry and Research Design:
Choosing Among Five Approaches (3rd edn). Los Angeles, CA: Sage Publications, Inc.

4. Tanya Custer et al (2015), The Utilization of the Anatomage Virtual Dissection Table in the Education of Imaging Science. Students Journal of Tomography \& Simulation.

5. Ian Chan et al (2015), The Effectiveness of Learning Anatomy and Medical Imaging Using the Anatomage table compared to Prosection. Radiologists- in- Training contest at the 2015 Joint congress on Medical imaging and Radiation Sciences.

6. Fyfe G., Fyfe, S., Dye, D., Crabb, H. (2013). Use of Anatomage tables in a large first year core unit. In H. Carter, M. Gosper and J. Hedberg (Eds.), Electric Dreams. Proceedings ascilite 2013 Sydney. (pp.298302).

7. J.Brown, S.Stonelake, W.Anderson, M.Abdulla, C.Toms, A.Farfus, J.Wilton (2015).Medical Student Perception of Anatomage - A 3D interactive anatomy dissection table. International Journal of Surgery.

Copyright: () the author(s), publisher. Academia Anatomica International is an Official Publication of "Society for Health Care \& Research Development". It is an open-access article distributed under the terms of the Creative Commons Attribution Non-Commercial License, which permits unrestricted non-commercial use, distribution, and reproduction in any medium, provided the original work is properly cited.

How to cite this article: Bharati AS, Kumari SN, Rani VS. A Study on Student Perception of Virtual Dissection Table (Anatomage) at GSL Medical College, Rajahmundry. Acad. Anat. Int. 2018;4(2):28-31.

DOI: dx.doi.org/10.21276/aanat.2018.4.2.8

Source of Support: Nil, Conflict of Interest: None declared. 